Article

\title{
Life Cycle Costing: Understanding How It Is Practised and Its Relationship to Life Cycle Management-A Case Study
}

\author{
Marianna Lena Kambanou(iD \\ Environmental Technology and Management, Department of Management and Engineering, Linköping \\ University, 58183 Linköping, Sweden; marianna.kambanou@liu.se; Tel.: +46-132-816-10
}

Received: 2 March 2020; Accepted: 10 April 2020; Published: 16 April 2020

\begin{abstract}
Despite the existence of many life cycle costing (LCC) methods, LCC is not widely adopted and LCC methods are usually further tailored by practitioners. Moreover, little is known about how practising LCC improves life cycle management (LCM) especially if LCM is considered emergent and constantly developing. In a manufacturing company, LCC is prescriptively introduced to improve LCM. In the first part, this study describes how various methodological choices and other aspects of practising LCC were the outcome of contestation and conformity with extant practices and not only the best way to fulfil the LCC's objective. This contestation can even influence if LCC is adopted. In the second part of the research, the implications of practising LCC on LCM are explored. LCC is found to positively propel LCM in many ways e.g., by spreading the life cycle idea, but may lead to a narrower understanding of the term life cycle resulting in the sustainability focus of LCM being overridden. The article also discusses how the findings can be taken into consideration when researchers develop LCC methods and when industry practises LCC.
\end{abstract}

Keywords: product-service systems; servitization; performativity; life cycle engineering; cost accounting; sustainability; research and development; R\&D; total cost of ownership; barriers

\section{Introduction}

In an effort to meet "the needs of the present without compromising the ability of future generations to meet their own needs" [1] multiple concepts, tools, and methods focusing on different challenges have been developed for companies to implement. Life cycle management (LCM) is such an umbrella concept, often viewed as an aggregation of tools and methods knotted together by life cycle thinking and aiming to minimize the environmental impacts of products and/or services over their life cycle [2-4]. One of the tools in the LCM toolkit is life cycle costing (LCC), a method for calculating the costs over the life cycle of a product and/or service [3,5].

There is an abundance of LCC methods. These are usually developed by researchers based on desktop research and/or a single case study and then prescribed to industry [6]. Therefore, they tend to be case or industry specific [7]. Despite this abundance of tailored, case-specific methods, LCC is not widely used [8,9]. When it is used, it is not to the level of sophistication described in published literature because practitioners tailor the LCC methods down further [6,7]. Although some research, mostly concerning buildings, has been conducted on the barriers to using LCC e.g., [6,9,10], few researchers have engaged in investigating what drives this need for tailoring upon tailoring [6,11].

The purpose of the first part of this research is to develop a deeper understanding about why LCC is not more widely used by practitioners and what drives this tailoring. This is done by drawing on practice theory (e.g., $[12,13]$ ) and its use in the field of organizational studies to view companies as a collection of practices that produce, reproduce, and transform the company $[14,15]$. Practices are 
"routinized sets of bodily and mental activities" [12]. A practice approach has been used in diverse fields e.g., the development and use of IT to support homecare work of elderly people [16] or the practice of monitoring patients through telemedicine [14] or active money management practice in the US mutual fund industry [17].

New or innovative practices contest extant practices $[14,15,17]$. The outcome of this contestation will influence, if and how a practice is practised in an organization [14,18], and by extension, if it will follow the general pattern of the practice. If LCC is conceptualized as a practice and LCC methods are conceptualized as prescribed or general patterns of LCC practice, then the introduction of LCC in an organization will contest extant practices. This can help to explain why despite the proliferation of LCC methods, its adoption is slow and why practitioners tailor it. The first research question is thus formulated.

RQ1: How can lack of adoption and tailoring of LCC methods be understood to be the result of contestation and conformity between LCC practice and extant practices?

To do this we use a case study approach where LCC was prescriptively introduced in a company to improve LCM. Over three years (2015-2018), the process of introducing and practising LCC e.g., methodological decisions, use of the results was documented and analysed. LCC was introduced at the case company to improve LCM and therefore, the second part of the research investigates their relationship. Despite being a part of the LCM toolkit, LCC was not developed for LCM or sustainability purposes $[19,20]$. When it is used with an explicit aim of decreasing environmental impacts or as part of LCM, then practitioners do not necessarily follow the prescribed methods such as environmental LCC $[6,21]$. It is unclear how tailored versions of LCC affect the outcome of LCM. Moreover, since the middle of the 2000s, little has been published on the use of LCC in the context of LCM because academic focus is on other LCM tools such as life cycle assessment (LCA).

To investigate their relationship, however, this research does not adopt the view of LCM, which is heavily grounded in the natural sciences, that advocates for its implementation as a normative set of rules or an unchanging state that comes into existence through careful planning and impeccable execution of various tools. Instead, as advocated in recent years by an increasing number of researchers that draw on the social sciences [22-24], an emergent and performative understanding of LCM is taken. LCM is thus viewed as a practice situated in other practices that emerge over time.

From this vantage point, both LCM and LCC are practices that are related but of different relevance where activities need to perform one influences the other (as well as other company practices). Investigating LCM and LCC from this perspective can help us go beyond a simplistic understanding of LCC as just providing LCM with costing results for decision-making purposes, to a force that propels an emergent LCM. Therefore, the second research question is formulated as follows:

RQ2: How does the practice of LCC propel an emergent LCM?

Although the objects of study are LCC and LCM, companies are bundles of practices that cannot be observed in complete isolation. At the case company, LCC was introduced as part of a prescriptive solution to challenges associated with the LCM of integrated products and services namely products-service systems (PSS). Subsequently, PSS is the third concept used in this research and provides the backdrop.

Based on the findings from the RQs, this research closes by discussing the implications of a practice approach on LCC method development as well as the managerial considerations when practising LCC. The use of practice theory in the development of sustainability focused tools and methods for industry is also discussed.

\section{Theoretical Background}

\subsection{A Brief Overview of Practice Theory and Its Elements}

Practice theories include a number of theoretical approaches connected by conceptual similarities that have become increasingly used to explain organizational phenomena $[14,15,18]$. Practice theory is 
essentially theories that "attempt to provide a new vocabulary to describe the world and to populate the world with specific 'units of analysis'; that is, practices" [14]. In accordance with practice theory, companies and other types of organizations are kept in place by practices, which are often ongoing and recurrent [15]. Practices, though, do not have perpetuity qualities; some will be used once, some will endure, some will fade or be transformed over long periods [14]. A new or innovative practice contests extant practices $[15,18,25]$. For some social scientists, practices are the backbones of social life $[13,26]$. Practices exist in a specific space and time and therefore, change over space and time [13].

In his seminal paper on practice theory "Toward a Theory of Social Practices: A development in culturalist theorizing", Reckwitz [12] uses the following elements to clarify the "praxiological world view": body, mind, things or objects, knowledge, discourse, structure/process, and the agent/individual. According to his positioning, practices are sets of bodily and mental activities that are routinized; he does not deal with practice change but describes its characteristics. Knowledge thus becomes a common way of knowing and discourse is a means to act in the world. Materiality and objects have a central role in enabling and constraining the practice. In organizations, structures and processes consist of routinized and formalized practices.

The role of individuals is emphasized in setting up practices, contributing to their dispersion, change, and even demise [14]. However, it is through what, Czarniawska conceptualizes as action nets that are stabilized connections of collective and repeated actions involving various groups within an organization or between different organizations, that action becomes legitimate practice $[27,28]$. Life cycle practices often depend on the existence of action nets [22]. Some further details concerning the elements of practice are given in Section 4 when they are used the case study.

\subsection{Life Cycle Costing}

Put simply, LCC is the aggregation of costs over the life cycle of an offering [29]. As discussed in the introduction, methodological frameworks are still sector specific, adoption by industry is slow, and practitioners tend to tailor the methods. This tailoring is encouraged by various LCC frameworks in order to meet the objective and goal of the LCC e.g., IEC recommends excluding costs that are expected to be identical between compared alternatives [30]. LCC's complexity lies in the scoping, the compiling of the cost inventory, the estimating of the costs and their inherent uncertainty, and in the interpreting of this information in the context of other information in order to make a decision [30,31]. One of the outcomes of the lack of a common methodological framework is that words are ascribed different meaning e.g., life cycle can be understood as cradle to grave or as just the part that a specific organization is responsible for [19,32] or as multiple life cycles [33].

There is ample research where LCC is used as a method for studying a phenomenon. However, research where LCC is the object of analysis is not as abundant and overwhelmingly focuses on the development of LCC methods [6] e.g., cost inventory compilation (e.g., [7,33]) and cost and uncertainty estimation $[34,35]$.

Some articles were identified that discuss barriers to using LCC or the reason for its tailoring but these exclusively concern construction projects. In these, i.e., Opoku [10], Goh and Sun [21], Higham et al. [8], the most commonly mentioned conditions that influence whether and how LCC is adopted are a lack of i) demand for LCC from the customer, ii) standard methodologies, iii) various types of data, iv) cost and uncertainty estimation methods, v) understanding/awareness of LCC and its methods, and v) software. This list is non-exhaustive but covers the major challenges. These articles, however, focus on the technical aspects and do not try to understand contestations or conformities between LCC and other practices that affect its use and tailoring.

Nevertheless, one study by D' Incognito et al. [9] groups barriers into behavioural, organizational, technical, and financial and finds that organizational culture i.e., the collective mind that distinguishes a group, to be the most relevant barrier for LCC use. This is a concrete finding that social aspects also play a role in how and if LCC is used. De Giacomo et al. [36] used an organizational learning theoretical lens to explore whether experience with green public procurement stimulates LCC learning and LCC 
capability development. They found that synergies do exist in specific contexts, thus acknowledging that a practice i.e., green public procurement can stimulate another practice i.e., LCC. This type of performativity between practices was also documented by Gluch et al. [6] who found that practitioners working with life cycle thinking in projects saw fewer hindrances to practising LCC than those who did not. The same study also showed that an LCC's "context of multiple and partly competing institutional logics" [6] affect how it is practised.

\subsection{Life Cycle Management as a Practice and Its Relation to Life Cycle Costing}

Sometimes LCM is used by practitioners and academics alike synonymously with product lifecycle management (PLM) i.e., "the business activity of managing, in the most effective way, a company's products all the way across their life cycles" [37] or as Bey puts it "LCM can, with full legitimacy and good reasoning be practiced without a focus on environment and sustainability" [4]. Usually LCM is very closely related to PLM, thus including life spanning management, but a major drive is environmental and resource efficiency and effectiveness $[3,38]$. It is this understanding that is adopted when LCM is used to support sustainability [24] and is also used in this paper.

Two different conceptualizations of LCM i.e., as a toolkit deriving from the natural sciences and as a social process deriving from the social sciences were discussed in the introduction. In the natural sciences derived conceptualization, LCC is a tool that provides the economic perspective of sustainability and provides quantitative financial information needed to make a decision [2,5]. Research in this area focuses on methodologically aligning LCC with LCA for parallel use e.g., Hunkeler et al. [19] or Bierer et al. [39] and on conceptually using LCC in environmental decision-making [20,40]. Neither of these discusses other synergies between LCM and LCC e.g., capability building or performativity.

Nilsson-Lindén, Diedrich, and Baumann [22] take the social sciences derived approach to LCM and study how life cycle practices emerge and perform LCM. Their findings from a longitudinal case study are that LCM is situated in life cycle practices, which emerge from local actors and that gradually connect and form action nets. These action nets stabilize and spread or dissolve. This research refers to all life cycle practices but LCC was not used at the case company.

\subsection{Product-Service Systems as a Practice}

PSS is defined as "an integrated bundle of products and services which aims at creating customer utility and generating value" [41]. When companies offer PSS, they offer their products as a service, thereby retaining ownership of the products and taking over portions of their customers' activities [42,43]. This extension of responsibility over the life cycle organically creates a need and initiates a discourse about life cycle thinking and PLM or LCM [44,45]. It also results in a shift of costs from the customer to the company while the revenue is spread out in smaller instalments over a longer period; therefore, LCC is considered key to understanding and making decisions [44,46]. Practice theory has been used when researching companies transitioning from sales to PSS, called servitization. Servitization has been conceptualized as integrated sets of practices and practices that become contested (see $[18,47]$ for a more detailed account).

\section{Method}

\subsection{Method Overview}

The study of practices requires thick descriptions of phenomena and cannot be done through surveys and interviews that occur a long time after the event [14]. Therefore, investigating practices is suited to in-depth case study research of contemporary phenomena, where the practice can be observed and the individuals carrying out the practice can be interviewed as close as possible to the events [25]. Consequently, this work uses the qualitative case study method (e.g., [48-50]) as the overarching research approach. 
The unit of analysis is the practice of LCC at the case company. Thick descriptions of decisions and events associated with practising LCC are given. Thick descriptions are interpretative rather than descriptive ([51] p. 880). When providing thick descriptions the researcher is interpreting an event or action or decision by providing context, meanings, intentions, motivations etc., that characterize it [52]. In this research, not only events but also their unfolding over time and their relationship to each other are taken into account. The first purpose is to provide thick descriptions of the events, actions, and decisions that result in LCC methods being tailored and/or not followed. The second purpose is to use these thick descriptions of events, actions, and decisions connected with LCC to see how they propel LCM. These descriptions are based on information gleaned from documents as well as observations and analysis of verbal communication during focus groups, interviews and activities such as cost data collection (see Section 3.3 and Table 1).

Table 1. Time line of interviews, focus groups, dissemination seminars at the case company (IpsosCo).

\begin{tabular}{|c|c|c|c|c|}
\hline Date & Participants & $\begin{array}{l}\text { No } \\
\text { Part. }\end{array}$ & Type & Id \\
\hline May 2015 & Project group & 5 & Start-up-Scope setting & G1 \\
\hline June 2015 & PSS and Remanufacturing & 1 & Scope setting & I1 \\
\hline October 2015 & Services & 2 & Data collection & G2 \\
\hline October 2015 & PSS and Remanufacturing & 1 & Scope setting & $\mathrm{I} 2$ \\
\hline November 2015 & PSS and Remanufacturing & 1 & Scope setting & $\mathrm{I} 3$ \\
\hline November 2015 & PSS and Remanufacturing & 1 & Scope setting & $\mathrm{I} 4$ \\
\hline November2015 & Services & 1 & Data collection & I5 \\
\hline December 2015 & Sales and customer service & 1 & Scope setting & I6 \\
\hline January 2016 & Product Management & 1 & Goal setting & I7 \\
\hline January 2016 & R\&D & 1 & Goal setting & I8 \\
\hline January 2016 & PSS and Remanufacturing & 1 & Intermediate result discussion & I9 \\
\hline January 2016 & Sales and customer service & 1 & Scope setting & $\mathrm{I} 10$ \\
\hline February 2016 & Services & 1 & Data collection & $\mathrm{I} 11$ \\
\hline February 2016 & PSS and Remanufacturing & 1 & Intermediate result discussion & $\mathrm{I} 12$ \\
\hline March 2016 & Services & 1 & Data collection & $\mathrm{I} 13$ \\
\hline March 2016 & PSS and Remanufacturing & 1 & Informational interview & $\mathrm{I} 14$ \\
\hline March 2016 & Project group & 5 & Focus group-cost estimation techniques & G3 \\
\hline March 2016 & Sales and customer service & 1 & Informational interview & $\mathrm{I} 15$ \\
\hline March 2016 & Services & 1 & Data collection & $\mathrm{I} 16$ \\
\hline April 2016 & Production & 1 & Data collection & $\mathrm{I} 17$ \\
\hline April 2016 & Transport & 1 & Data collection & $\mathrm{I} 18$ \\
\hline April 2016 & Sales and customer service & 1 & Informational interview & I19 \\
\hline April 2016 & Sales and customer service & 1 & Informational interview & $\mathrm{I} 20$ \\
\hline April 2016 & Services & 1 & Data collection & $\mathrm{I} 21$ \\
\hline April 2016 & Sales and customer service & 1 & Informational interview & $\mathrm{I} 22$ \\
\hline May 2016 & R\&D & 1 & Information collection & $\mathrm{I} 23$ \\
\hline May 2016 & Services & 1 & 1st round result discussion & $\mathrm{I} 24$ \\
\hline May 2016 & Project group & 6 & Focus group-1st round result discussion & G4 \\
\hline May 2016 & Services & 1 & 1 st round result discussion & $\mathrm{I} 25$ \\
\hline June 2016 & R\&D & 1 & 1st round result discussion & $\mathrm{I} 26$ \\
\hline August 2016 & Sales and customer service & 1 & 1st round result discussion & $\mathrm{I} 27$ \\
\hline March 2017 & Services & 1 & Adjustments to costing techniques & $\mathrm{I} 28$ \\
\hline April 2017 & Sales and customer service & 1 & Adjustments to costing techniques & $\mathrm{I} 29$ \\
\hline April 2017 & R\&D & 1 & Adjustments to costing techniques & $\mathrm{I} 30$ \\
\hline June 2017 & Sales and customer service & 1 & Informational interview & I31 \\
\hline June 2017 & Accounting & 1 & Informational interview & $\mathrm{I} 32$ \\
\hline June 2017 & Sales and customer service & 1 & Informational interview & I33 \\
\hline June 2017 & Accounting & 1 & Informational interview & $\mathrm{I} 34$ \\
\hline November 2017 & Project group & 6 & $\begin{array}{l}\text { Final result presentation and focus group } \\
\text { on recommendations }\end{array}$ & G5 \\
\hline November 2017 & Focus group & 8 & $\begin{array}{l}\text { Final result presentation and focus group } \\
\text { on recommendations }\end{array}$ & G6 \\
\hline December 2018 & Top Management & 3 & $\begin{array}{l}\text { Final result presentation and focus group } \\
\text { on recommendations }\end{array}$ & G7 \\
\hline January 2018 & Top management & 10 & Dissemination & G8 \\
\hline May 2018 & Middle management company wide & 18 & $\begin{array}{l}\text { Dissemination and discussion about } \\
\text { findings-future }\end{array}$ & G9 \\
\hline May 2018 & Middle management company & 14 & $\begin{array}{l}\text { Dissemination and discussion about } \\
\text { findings-future }\end{array}$ & G10 \\
\hline
\end{tabular}


Practice theory is used as the analytical lens. LCC is conceptualized as a practice and LCC methods are conceptualized as prescribed or general patterns of LCC practice. The introduction of LCC in an organization is expected to both conform and contest extant practices. Two specific scientific contributions are central to this analysis. The first is the work by Nicolini [25], who suggests that when studying practice there should be an appropriate balance between zooming in on the details of the studied practice and zooming out in order to observe the effects of performing the practice on the other organizational practices. Therefore, in the first part of the research, which focuses on understanding the contestation and conformities between LCC practice and extant practice, the researcher kept on zooming in on the details of LCC practice and then zooming out.

To further structure this part of the research and mitigate the risk of leaving out elements of a practice, a second article by Reckwitz [12] is used. Although the elements presented by Reckwitz [12] i.e., body, mind, objects, knowledge, discourse, individual, and structures refer to routinized practices and not to new practices like LCC, they are still key elements of practices and contribute to maintaining a broad perspective during the analysis.

The second part of this research zooms out of LCC to view its relationship to a specific practice, LCM. The purpose of zooming out of LCC to its relationship with LCM is to identify how the efforts needed to perform LCC, including the process of contestation and conformity to extant practices as described in the first part of the research, will drive, propel, and provoke LCM practice, which is constantly evolving.

\subsection{Case Company and Background for Introducing LCC}

IpsosCo was founded in Sweden after the 2nd World War and since then has manufactured and sold the same type of industrial equipment, thus attaining a superior technological knowhow and a strong brand in the global market. Although aftersales services e.g., repairs were introduced as early as the late 1950s, over the last couple of decades IpsosCo also offers PSS through availability contracts. When offering PSS, IpsosCo retains the ownership of the industrial equipment and takes over portions of the customers' activities such as maintenance and operational monitoring which are included in the monthly fee stipulated by the contract. They also have a unit where some equipment returning from a contract is remanufactured and then utilized in new contracts or sold. PSS are a substantial portion of IpsosCo's revenue.

When providing industrial equipment through traditional sale, the focus is on designing and manufacturing as well as achieving the best quality to price ratio at the end of production. The responsibility for the equipment ends when it is sold to the customer. By offering their products as a service and retaining ownership, IpsosCo's incentives shift, as they are responsible for a larger part of the life cycle. This change is profound, affecting many aspects such as design, the business model, financial incentives and value creation. Furthermore, it has created a space or even a need for new practices.

Over many years, IpsosCo and the University of Linköping have had joint research projects, master theses and PhD research to explore the phenomenon of PSS. In early 2015, after mapping out the learnings from the joint collaboration over the years, the use of costs and values over the life cycle in order to improve the LCM of the PSS was identified as a crucial next step. IpsosCo financed a joint three-year research project with Linköping University called "Analysis of Life Cycle Costs and Values to Improve Life Cycle Management."

As part of this project, LCC was introduced as a practice with the help of researchers. The purpose of introducing the LCC was to:

- Understand in detail the change in the cost structure and cost drivers between PSS and business-as-usual;

- Compare the LCC for various offerings for the same or for different customers;

- Identify uncertainties;

- Identify additional ways of using LCC to improve LCM. 
The project and subsequently, the LCC were initiated by top management who also became the board of the project. There was a project group consisting of 5 to 6 key persons from R\&D, product management, services, sales and customer service, and PSS and remanufacturing. There were some changes in members because of people changing jobs and at one point, a member was added. In total, 24 members of staff were interviewed or joined the focus groups and over 50 were involved in the project by joining the final dissemination seminars and follow-up discussions. The research was both participatory and action oriented.

LCC was performed for several types of product service combinations as well as customer segments. A timeline of activities is given in Table 1. The first round of LCC results was calculated by May 2016 and discussed in focus groups and interviews and subsequently, developed further. The final LCC results were ready in August 2017. After this, three focus groups were held to assist the researcher in interpreting the results and deriving recommendations. Three dissemination seminars were held to spread the results and recommendations and also to provide the participants with time to discuss the findings and future directions.

\subsection{Data Collection and Analysis}

\subsubsection{The Role of the Researcher}

The researcher had a central role in practising the LCC at the case company. The researcher was responsible for, among other things, arranging the meetings, performing the calculations, collecting data, and leading the process of deriving recommendations. However, everything was done in collaboration with members at the case company. Methodological decisions such as cost estimation techniques, cost inventory compilation, prioritization of topics on which to obtain complimentary information, level of ambition and the identification of individuals to attend an activity were guided by the project group, the board of the project and by other members of staff. For example, the cost inventory went through multiple reviews and was updated even 1.5 years into the project.

\subsubsection{Documents}

A range of documents was examined by the author such as sustainability reports, previous research projects with the university, and information on the website to understand the IpsosCo and the life cycle of its PSS. Documents were also used to obtain information used in the LCC e.g., excel files, emails, and contract estimation parameters. A final category of documents included the written documentation of the practice e.g., minutes of meetings, notes from observations, project reports, and emails with comments.

\subsubsection{Interviews, Focus Groups, Activities, and Dissemination Seminars}

As shown in Table 1, interviews and focus groups were conducted over an extended period of time and included a broad set of respondents and various types of themes related to LCC e.g., scope and goal setting and data collection. In most cases, the interviews were semi-structured [53] based on an interview guide or list of topics to be covered. As recommended by Patton [54], the focus groups included 6-10 participants. Most of the interviews and focus groups were recorded and stored digitally and selectively transcribed [53]. Minutes were written directly after the majority of interviews and focus groups and then given to a company representative to review and confirm.

\section{Results on Contestation and Conformity between LCC Practice and Extant Practices}

In this section, the ways in which the practice of LCC was found to contest and conform to extant practices at IpsosCo are described as well as the outcomes of these contestations or conformities that lead to both formal and informal decisions of how LCC was practised i.e., methodological decisions. Although the findings are thematically organized according to the elements of practice described by Reckwitz [12], this categorization is based on what the researcher perceived as the strongest element 
in an event because as Reckwitz points out, the elements are interconnected and cannot be reduced to a single element. This interconnectedness also means that the results in this section cannot be completely separated from the results of LCC's relation to LCM in the next section.

\subsection{Body of the Individual}

Extant practices include "routinized bodily activities" e.g., writing, talking, and even mental and emotional activities which happen in the body [12]. At the outset of the project, the project group, consisting of key persons from different departments was assembled and they met in person (G1). Although the description of the task was easily understood and the meeting (G1), which included scoping, ran smoothly, at the end of the meeting the group requested an email from the CEO stating the purpose of their participation. At this stage in the proceedings, this rather superfluous request was most likely the result of a reaction to a new bodily activity i.e., it was a "physically unusual" event to be sitting in a meeting room with specific individuals that do not usually meet, rather than a lack of understanding regarding the task or an inability to discuss with each other. The request is regarded as superfluous because the project and the team had been initiated and assembled respectively by top management and documentation had been provided and the meeting reached its goal. After the third meeting (G4) and despite the absence of the email from the CEO, the request did not appear to be deemed so urgent possibly because the meetings had started to become routine.

There were though other instances when the bodily activities involved in LCC were almost identical to other practices. For example, during the six data collection meetings (G2, I5, I11, I13, I16, I21) and follow-up calls with the individual assigned the task of collecting the bulk of the cost data, the researcher had the opportunity to observe this activity and ask about its compatibility with other routines. Cost data collection for the LCC was similar to the everyday routines of generating cost reports and answering ad hoc queries or filling in excel files related to costs requested from any part of the large organization.

\subsection{Mind of the Individual}

Extant practices also include "routinized mental activities" defined by the individual's understanding and interpretation of the world, desires, and emotions or knowing how to practise something [12]. In order for someone to perform a practice i.e., LCC, the mind and body of the individual need to align to the patterns of this practice i.e., LCC method. The mind of the individual and collective knowledge cannot be easily distinguished and categorized; therefore, the categorization described here is by no means absolute.

The first time LCC was introduced to an individual i.e. during the very first meeting of the project group (G1) and subsequent individual meetings with them (I6-I8, I10) as well as during interviews (I1-I3, I27, I31-I34) and data collection activities (I5, I17, I18) with other staff members it was clear that the concept of LCC is easily understood. Most of the people interviewed had encountered this term before i.e., during their higher education, or even through work experiences. Therefore, although they had not practised the routine per se, the mental pattern, at least on the surface was familiar, and when it was not, then the familiarity of the monetary metric made it easy to comprehend giving at least a starting point from which to align with the pattern of practice.

Despite this apparent basic understanding, during the six data collection meetings with the same individual (G2, I5, I11, I13, I16, I21) it became clear that the mental pattern for finding the specific costs differed greatly from the existing cost data collection patterns. This is the main reason why six data collection events were needed and not just one or two.

As the project progressed and especially in the focus group in May 2016 (G4), it became clear that the knowhow of enacting the practice was based on diverging individual interpretations. Long discussions centred on issues that were understood or interpreted differently; one of which stands out particularly: that of the understanding of the life cycle. One individual considered the life cycle as only the first contract (product manager), two individuals included subsequent contracts with the same 
customer (service managers), and one individual all contracts even after remanufacturing (regional sales director of new and remanufactured offerings) while another offered no opinion (R\&D). This perspective of the life cycle coincided largely with the areas of responsibility that they had in other practices they performed. This observation is in line with practice theory where an individual generally understands a practice in the context of other practices (s)he carries out.

\subsection{Objects-Material and Symbolic}

When a practice is carried out, specific things including documents and images are used in a specific way e.g., a microphone not only amplifies the voice but also gives the person holding it the authority to speak. Objects therefore, both enable and limit the bodily and mental elements of practices [12]. Materiality is a central concept in practice theory, as it is often through objects that a practice can be systematically reproduced [15]. In this section, both material and symbolic objects are described.

A central object in the LCC practice was the product itself. The object of the LCC analysis was a PSS, but the product had the prominent position e.g., only costs directly connected to the product came to participants' minds when brainstorming the cost inventory (G2, G3, I2, I3). Service was a secondary object of concern subsumed by the object that historically has had a greater significance. For example, based on interviews with sales managers and rough calculations (I6, I15, I19), the costs of selling and negotiating with the customer were found to be both significant and case specific but nevertheless, the central standpoint was that these are necessary costs as are overhead costs and are not directly connected to specific products. Therefore, they are (and should be) managed in a different way and not as part of LCM. This understanding was also reflected in the organizational scheme, as the sales companies were subsidiaries to the main company and in the data system that allocated these costs to departments, customers, or overheads. This standpoint can be summarized by the following statement:

"this is not how we slice the cake ... trying to allocate these costs (sales and customer costs) to products will be more effort than doing the LCC".

The second object that constrained the mind was the company itself. The general assumption was that costs owned by the company should be included, thereby equating LCC with the total cost of ownership. The physical walls of the organization become the mental walls of the practice. Therefore, many stressed the importance of also calculating customer costs for improved LCM but as a separate calculation. Ergo there is an understanding of "our life cycle" versus "their life cycle" rather than the product's or PSS's life cycle. Although the purpose of LCC was LCM, which has inherent environmental objectives, nobody suggested using environmental LCC. Environmental LCC includes internal and external costs that are expected to be internalized, covered by all actors, and recommended for LCM [19,32]. The researcher did not bring up the topic, as she perceived it to be possibly too far away from the individual's understanding of LCC.

A third and crucial group of identified objects were the documented interim and final LCC results and project deliverables including reports, minutes, presentations, pie charts, and other images. The results from the first round of calculations, shown only to the project group (G3, G4) and some interviewees (I17, I24-I27, I34) were surprising to many of them. One interviewee expected production costs to dominate more (I17); two project members were surprised that operational costs for similar types of products and intensity of use differed greatly at different customer sites (G4). Another project member was concerned whether all costs had been included because (s)he expected operational costs to be higher (G4). The final round of results, when shown to top management (G7, G8) and in the dissemination seminar (G9, G10), was also met with some surprise and lively discussions ensued despite many claiming that they had no predetermined expectations.

Of course, these reactions show how individuals interpret LCC results differently but the point of presenting these research findings in this section is to demonstrate that the LCC results are objects 
that both create the conditions for reproducing LCC practice and demonstrate the inadequacy of extant practices.

More specifically, the results helped to concretize and visualize the life cycle idea in the company firstly, by putting life cycle stages on the same pie chart e.g., production and operation. Therefore, these images, which initiated the biggest interest during the dissemination seminars (G7-G10) attended by more than thirty participants, contributed to creating a common understanding of the life cycle and the importance of LCM and laying the groundwork for the reproduction and establishment of life cycle practices.

Additionally, but equally importantly, the results were not generic but very specific configurations of a product deployed at a specific customer. The diversity of the findings emphasized plurality and diversity of what a life cycle is and looks like for different PSS and more specifically, the distribution of costs over the life cycle. For a company used to clearly defined production costs that are almost identical for two products in the same category, the objects presented a new perspective of plurality, and initiated a discussion of whether the life cycle of PSS can be accounted for and managed through generic models or whether case-by-case decisions should be the focus. As can be seen by the number of dissemination activities, disseminating these objects e.g., reports, charts was considered important.

\subsection{Collective Knowledge}

Knowledge is the collective way of understanding, feeling, desiring, and knowing contained in a practice [12]. Knowledge can be interpreted by the mind of an individual agent but in this section we refer to collective knowledge of the people in the organization. It is usually implicit and grounded in a specific historical and cultural context. IpsosCo has a long tradition of continuous improvement in product development and manufacturing and a strong engineering culture. This has led to a common understanding that well-structured processes and technical knowledge is the foundation of superior products.

This knowhow was the point of departure for practising LCC as a process to be based on sound data and optimized cost models to be universally applied in all cases. This approach, however, became contested when discussing how to calculate residual value (G3, G4, I2, I6, I20, I27, I29). The first option was to use the "book value" based on accounting norms because it was based on a precise and reproducible estimation technique and already calculated for the PSS under study. This argumentation was grounded in IpsosCo's strong engineering tradition. The second option was to use the estimated price in the second hand market. This initiative was strongly supported by the managing director of sales who reasoned that the "market value" is in many cases higher than the "book value" at the end of a contract. $\mathrm{S}$ (he) also reasoned that it is a better measurement to use for managing the life cycle because it captures the trade-off between higher service and production costs and profits over the life cycle. This is exactly the type of trade-off that could contribute to resource efficiency, prolonging the life cycle of products, and even increase IpsosCo's profitability [42]. Additionally, another interviewee mentioned that keeping "market value" high will lower IpsosCo's risk in the event that the customer breaks the contract early. The "market value" though, is very hard to estimate and veiled in uncertainty so the "book value" was used, although everybody understood the importance of using "market value" in LCM. This was echoed by the board of the project who were additionally slightly concerned that the harmonized way set up by lawyers and accountants to calculate the "book value" could be undermined by introducing other measurements.

This example is indicative of the tensions that arise from applying the old knowhow of extant practices, unaltered to the new practices of LCC and LCM. Knowing is also feeling and desiring and in this case, part of this knowhow is an expected level of control and a desire for countable knowledge derived from precise and reproducible measurements. This approach cannot support LCC and LCM because there is a lack of life cycle data and many factors that influence the life cycle which are out of IpsosCo's control and area of jurisdiction e.g., customers' behaviour and the operational environment. 
This was obvious because a large number of the interviews focused on estimating costs because not enough data was available as well as trying to understand what factors influence the costs.

Technological developments will make more data available and it is possible through business model changes e.g., automation and stronger contracts to gain more control over the influencing factors but it might be many years if not decades before IpsosCo can conduct LCC and LCM in line with their current knowhow. It remains unresolved if LCC and LCM will be practised sub-optimally with the current understanding, desires, and wishes or in a new form or if IpsosCo will postpone their practice until technology and automation catch up. This trilemma is depicted in Figure 1.

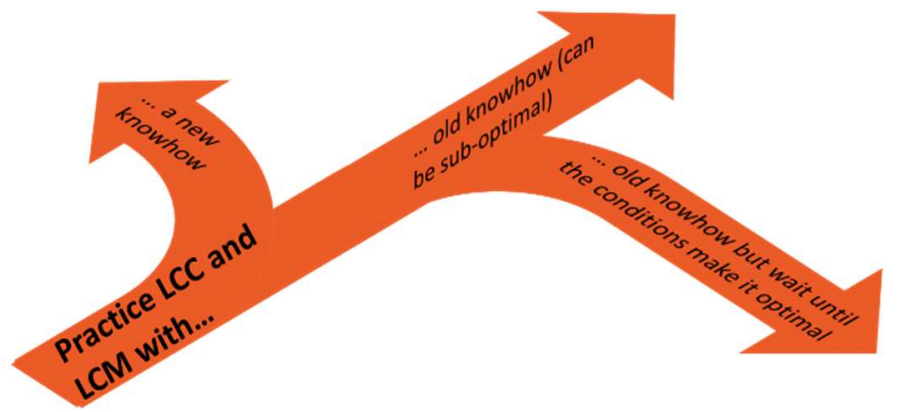

Figure 1. Possible knowhow when practising life cycle costing (LCC) and life cycle management (LCM).

\subsection{Discourse-A Common Denominator}

Discourse is a type of practice [12]. Discourse is a part of LCC practice and most of the findings described in Section 4 are a direct result of observing and participating in discourse, so it would be possible to categorize most findings as discourse practices. However, the aim is not to analyse each discourse practice of LCC but LCC as practice. Therefore, it is important to point out that the practice of discourse involving diverse individuals (G1, G3-G6) was crucial to many aspects of LCC practice e.g., scoping and costing techniques for LCC.

During the discussions (G3-G6) it was revealed that common meaning was not always ascribed to particular words. This was the case in two types of instances. The first was when different meanings were ascribed to a word by different groups within IpsosCo and the second was when IpsosCo ascribed a different meaning to a word than that ascribed by the broader public. The most notable example is the compound word "life cycle" perceived differently within the company and at variance with the ISO definition (G3, G4). A more mundane example was a "cost code" for service technicians that is understood and used slightly differently in two different countries (I22). The practice of LCC and LCM will need to be supported by language, which is commonly understood throughout IpsosCo, regardless of the department or daughter, or sister company one is employed in. Common meaning of words will not only influence the practice of LCC but also the dissemination of the results and its influence on LCM.

Language is also performative and the word cost, which is central to LCC, has negative connotations, thus connecting the life cycle idea to a negative concept rather than a positive idea like value or revenue. An indicator of this is that although LCC can include the calculation of revenue [19], when this was suggested by the researcher, it was initially questioned by members of the project team.

Discourse is also a means to act and opportunity for discourse has to be provided; therefore IpsosCo and the researcher agreed that the dissemination seminars would include time for the participants to discuss LCC results and practice.

\subsection{Individuals-The Role of RED Engineers}

Individuals carry out practice, and each develops an understanding of a practice based on how the body and mind have been shaped through performing and being performed by all the practices the individual carries out [12]. 
Individuals perceived the importance of practising LCC differently. Out of the project team, two members strongly supported the initiative by going out of their way to facilitate its progress by identifying key persons, establishing contact with them, and motivating them to get involved. The others simply did what was expected. To identify the amalgam of practices that motivated this behaviour goes beyond what was explored or could be observed within the project.

During the last two focus groups (G5, G6) where LCC results were used to discuss recommendations for LCM and the dissemination seminars (G9, G10), members from R\&D took leading roles; they also lead the process of formalizing the structures in order to establish LCC. From the transcripts, three reasons can be identified. The first is that because of offering PSS, R\&D has identified a need for tools like LCC because they conceptualize LCC as a tool that helps them understand the trade-off between design decisions and life cycle costs (at least until the end of the contract) instead of production costs. The second reason is that R\&D uses tools and methods and therefore, LCC practice coincides with their perception of how to perform practices. From these two findings, it can be concluded that the practice of design strengthened the legitimacy of LCC practice.

The third reason cannot be derived from practice theory but is associated with Czarniawska's action nets, which are emerging in the R\&D department as stabilized connections. The efforts of the $R \& D$ are further discussed in the structure and processes section.

\subsection{Structure and Processes}

Although Reckwitz [12] focuses on the routine structure, he also discusses the temporal nature of structures and routines and their dissipation or rupture when a crisis occurs as well as discussing the inadequacies of the practice and the individuals' knowledge to meet the needs when in such a crisis.

LCC was introduced by top management with the help of researchers because of such an identified rupture; the extant routines are not centred on offering products as a service but rather on the sale of products. LCC was introduced at IpsosCo as a practice and this whole research focused on addressing how this practice contested and conformed to extant practices. However, this top down action from management coincided well with the local understanding at R\&D level that the extant routinized practice of R\&D needed altering because of the PSS. This is why R\&D initiated a follow-up project between 2018-2020 to include LCC and other learnings from the project in the R\&D processes. However, practising LCC created other ruptures, as mentioned in Section 4.3.

\subsection{Discussion}

Although presented in independent chapters the elements of practice are deeply interrelated and causality for all findings described here can be linked to more than one element. Even Reckwitz [12], whose basic elements are used to structure the analysis, warned against trying to reduce a practice to its elements. Therefore, the elements are not used or recommended as a framework, they are used to keep the researchers perspective broad and to structure the results. The categorization is based on what the researcher interpreted as the strongest element in an event.

Some of the individual findings have been confirmed by other authors. For example, Palo et al. [12] used practice theory to investigate offering PSS and also found that the materiality of the product subsumes the service. Lack of data for LCC has been identified as a barrier $[8-10,21]$ but the findings in this research expose a hesitancy to find data and develop estimation techniques because they may come in conflict with extant costing practices.

Gluch et al. [6] found that managers working with lifecycle thinking were likely to see fewer hindrances to adopting LCC and this research confirms this and also expands the finding to individuals who also have expertise in working with tools e.g., R\&D staff and individuals who are involved in other practices affected by lifecycle e.g., PSS and remanufacturing. 


\section{Life Cycle Costing's Relationship to Life Cycle Management}

\subsection{Life Cycle Costing propelling Life Cycle Management}

In this section the findings concerning how LCC propelled LCM or created the conditions for practising LCM are presented. These do not include descriptions of its precise use e.g., as a key performance indicator or to map data insufficiencies.

\subsubsection{Background}

IpsosCo has developed environmental initiatives and put efforts into being perceived as an environmentally friendly company by publishing sustainability reports since 2013, adopting codes of conduct and various environmental policies. The point of departure for the project also included environmental considerations. The joint letter of intent, which provided the setting for the project, stated that the joint long-term aims of both the university and IpsosCo were:

First, both parties aim at carrying out research with world-class scientific quality contributing to global competitiveness of the Swedish manufacturing industry. The second aim is to enhance the contribution to each party's education $(\ldots)$. The third aim is to contribute to society both on the regional and national scales in terms of economic growth, job creation, and environmental sustainability.

The description of the project itself used the word LCM repeatedly without, however, including a definition of LCM. LCM was a concept that preceded the introduction of LCC in the case company. Starting from the assumption that LCM is a desired organizational activity that should be practised according to environmental or sustainability considerations and a full life cycle perspective, then LCC at IpsosCo was found to propel an emergent LCM towards and away from this ideal practice.

\subsubsection{Desired Propulsion}

LCC positively propelled LCM in many ways. First of all, the practice LCC may create the conditions needed to introduce and spread life cycle thinking as well as highlight a need for LCM. To this end, the results of LCC visualized the plurality of the life cycles for different PSS in terms of cost and profit distribution over the life cycle and the length of viable life, and generated profit per PSS (Section 4.3). After presentation of these results at the final group meetings (G6-G10) the rest of the discussion was framed by a common understanding of "an eminent need to manage costs and profits across the life cycle through LCM." The outcomes of LCC thus legitimized the practice of LCM.

At the level of practice, LCC contests various elements of extant practices, and by doing so aligns or preps them for LCM. To this end, LCC introduces more cooperation and discussion between people from different departments and initiates a process of developing common understandings for LCM (Section 4.1, Section 4.3, Section 4.5). This is done through discussions about defining the life cycle (Sections 4.2 and 4.5), what activities to include e.g., sales and marketing (Section 4.3), and how to estimate costs e.g., residual value (Section 4.4). Objects are created that further support this process and objects that constrain the process can be identified (Section 4.3). The practice of LCC also creates a forum for meeting other individuals with similar understanding (Section 4.6) and creating a point of departure for building the action nets needed to support the spreading of life cycle thinking and LCM (Section 4.7).

LCC's elements also conform to various elements of extant practices. Cost accounting is conceptually and linguistically understood in the organizational context and profitability is universally accepted to be of paramount importance and consequently, everyone can relate to it (Sections 4.2 and 4.6). Because of this familiarity, some data structures exist (Section 4.4), and some individuals have the capability to interpret LCC results based on previous experiences (Section 4.4). Finally, LCC can be connected to other crucial practices such as product development (Sections 4.6 and 4.7). 
This mixture of contestation and conformity makes LCC a very useful life cycle practice to introduce at the initial and intermediary stage of an emergent LCM that matures over time.

\subsubsection{Undesired Propulsion}

There were two ways that LCC was observed to propel LCM away from the idealized practice. The first concerned the understanding of life cycle. Defining the life cycle according to the task and excluding costs that are either perceived to be identical between compared alternatives or not influential to decision-making, is in line with LCC methodologies [30]. Moreover, the PSS at IpsosCo can be offered through multiple contracts and can include or exclude remanufacturing. As a result, the individuals at IpsosCo had ample opportunities to lay their own interpretation on the length of the life cycle and the activities to be included (Section 4.2, Section 4.3, Section 4.5). Notably no one suggested setting the moment the product reached a recycling facility as the boundary; therefore, all suggestions were of the narrow variety. The question is whether this narrower definition of the life cycle in LCC will provoke a narrower understanding of the life cycle in LCM. It may also strengthen and legitimize an already narrow definition of the life cycle in LCM or have no effect at all. If LCM is emergent and situated in life cycle practices as Nilsson-Lindén et al. propose [22], then LCC can propel LCM toward this narrower view of the life cycle and this was observed at the case company.

A second way that LCC might propel LCM away from its idealized conceptualization concerns the understanding of "environmental burdens." LCC aims at cost savings of resource such as materials, energy, transport but also human resources [29,30]. One of the aims of using LCC in LCM at IpsosCo was to reduce the resource use across the life cycle, not only for cost saving reasons but also for environmental burden reduction. This sentiment was not only expressed by the board but also by the project members. The hitch is that many environmental burdens are neither exclusively related to resources nor covered by LCC (even if applied to the whole life cycle) and prices are not indicative of "environmental burden" because they do not include externalities [19,40]. LCC can propel an understanding of LCM centered on resource efficiency, which does not include the breadth of environmental burdens.

These two ways of propelling LCM labelled here as "undesirable" might not create any problems when managing the life cycle from a business perspective, similar to PLM (see Section 2.3), but could potentially negate the goal of environmental improvements associated with LCM due to burden shifting and sub-optimization or exclusion of crucial environmental burdens [55].

\subsection{Life Cycle Costing, Life Cycle Management, and Other Practices}

LCC is just one of the practices e.g., LCA or design for the environment that propels LCM [22]. It is the net force of these practices, and not just LCC, that will define LCM in any given moment. LCM is performative and therefore will also propel LCC, in a two-way process. For example, a central vision in IpsosCo's sustainability reports is "eliminate waste" which is strongly grounded in resource efficiency. This understanding can reinforce the understanding in LCC of costs as resources; their joint force can increase the potential of other environmental actions being sidelined in LCM.

Another example relates to PSS. By offering PSS, the incentives of LCM are aligned with the companies incentives by giving it more or full responsibility of the life cycle [42,56]. At IpsosCo this is partially true for the first and second life. What happens if the product has more than two lives? Then LCM and business incentives are no longer aligned. Therefore, PSS that now propels and legitimizes LCM, might later constrain LCM. PSS also plays an important role in highlighting the service aspect of the offering, which as discussed in Section 4.3. is often of secondary importance to the product, thereby supporting the mental patterns needed for LCM.

Although this research did not investigate in depth other practices' effect on LCC and LCM, it is important to note that they exist. 


\section{Concluding Discussion}

\subsection{Theoretical Contributions}

The point of departure for this article is to understand why despite the proliferation of LCC methods, LCC is neither widely adopted by industry nor practised according to these LCC methods i.e. practitioners excessively tailor LCC methods. To do this, LCC is conceptualized as a practice and LCC methods are conceptualized as prescribed or general patterns of LCC practice. According to practice theory, a new practice will contest extant practices $[14,15,17]$.

Based on a case study where LCC was introduced as part of an ongoing LCM effort, this research describes different instances where LCC contested and conformed to extant practices and the outcome of this contestation and conformity defined how LCC was practiced e.g., scoping, goal setting, cost inventory creation, cost estimation technique selection and interpretation. Although researchers know and even encourage practitioners to tailor LCC methods to meet the goals and objectives of LCC [30], it is exposed here that tailoring also happens as a result of its contestation and conformity to extant practices and not only because it is the best way to meet the goals and objectives.

This conceptualization of LCC not as a tool, which is universally applied and implemented according to a prescribed methodology but as a practice performed by social elements emphasizes its plurality and case specificity. This plurality highlights a challenge, namely that if the practice of LCC diverges too much from the prescribed or general pattern of practice i.e., LCC methodology, then the LCC might not be effective in fulfilling the aims that it was meant to fulfil. For example, at the case company, there were tensions whether to use "book value", which is commonly used for their costing accounting, or "market value", which is recommended by the LCC method, as an estimate of residual value (Section 4.4), this decision has profound effects on the LCC results.

This conceptualization of LCC and the subsequent case study findings have implications for how LCC methods are developed and formulated. Some of these are presented in Table 2.

This conceptualization of "conducting a method" as a "practice" and a "method" as a "general pattern of practice" may also be useful in understanding if and how methods and tools are generally used or practised by companies. This is especially relevant in the field of sustainability, where despite the proliferation of sustainability and sustainability-related assessment methods and tools (see e.g., [32,57-60]) they are still not commonly practised [57]. This also contributes to industry not moving faster towards sustainability. The findings show that these methods and tools could contest current practices and the outcome of this contestation can lead to them not being adopted or to them being incorrectly used. It could also mean that companies choose methods that fit well with their extant practices rather than those that are best suited to deal with the challenges at hand.

Although various articles discuss barriers and drivers of method implementation and use, few researchers make use of social theory and practice theory. It is another way of investigating the world, involving social constructs, based on in-depth analysis rather than surveys and after the event interviews. Therefore, it provides other types of insights. Insights, which are probably needed for all types of sustainability-related methods in order for them to become used and routinized in the right context and practiced in such a way that they fulfil their aims. The outcome of this research suggests that the research community can learn from more integration of social theories with the engineering discipline in order to understand how methods and tools are practised. The goal of this integration is to increase the number of companies where sustainability-related methods are used and routinized and thus contribute to the company's sustainability efforts.

The research also provides insights on the relationship between LCC and LCM. Of course, LCC is used in LCM decision-making to aid the choice between two or more alternatives e.g., configurations $[30,61]$. From this perspective, LCC can be used in many specific instances of LCM decision-making but it is not the purpose of this research to identify them. The focus here is on how practicing LCC, including contestations and conformities with extant practices, will affect LCM practice. The findings from IpsosCo show that LCC highlights inadequacies of extant practices to deal with the 
life cycle as well as initiates life cycle thinking and discussions about how to approach life cycle practices and how to make methodological decisions (see Section 5.1 for a more comprehensive explanation). This makes it especially useful to practise LCC when LCM is first introduced or not widely practised. It is also possible that LCC would reinforce a narrow understanding of the term life cycle and what "environmental burdens" are. It is important to note that LCM also propels LCC and other practices that make up the organization. This research is the only identified work that conceptually investigates the relation between LCC and LCM using the practice theory.

Table 2. Implications of results for development of LCC methods.

\begin{tabular}{|c|c|c|}
\hline & Findings & Considerations for LCC method development \\
\hline 1 & $\begin{array}{l}\text { LCC is tailored based on the outcome of its } \\
\text { contestation and conformity with extant practices }\end{array}$ & $\begin{array}{l}\text { Limit flexibility of LCC method on key issues. } \\
\text { (especially important if LCC is used for LCM) }\end{array}$ \\
\hline 2 & LCC is an emergent practice & $\begin{array}{l}\text { Include different LCC stages or levels that a company } \\
\text { advances to over time }\end{array}$ \\
\hline 3 & LCC becomes practice through repetition & $\begin{array}{l}\text { 1. Engage individuals repetitively during the LCC } \\
\text { process } \\
\text { 2. Disseminate intermediary LCC results }\end{array}$ \\
\hline 5 & $\begin{array}{l}\text { Individuals practice LCC differently influenced } \\
\text { by the extant practices they perform }\end{array}$ & $\begin{array}{l}\text { 1. Include individuals from across the lifecycle } \\
\text { 2. Clearly define key concepts e.g. lifecycle } \\
\text { 3. Carefully match appropriate individuals to LCC } \\
\text { activities } \\
\text { 4. Carefully consider how extant practices might } \\
\text { constrain an individual from following the LCC method }\end{array}$ \\
\hline 6 & $\begin{array}{l}\text { For traditional product-manufactures the } \\
\text { "product" is in the centre }\end{array}$ & $\begin{array}{l}\text { Emphasize the service aspect and provide detailed } \\
\text { advice on how to include it }\end{array}$ \\
\hline 7 & $\begin{array}{l}\text { The perception of the "company" constrains the } \\
\text { lifecycle perspective }\end{array}$ & Clearly define key concepts e.g. lifecycle \\
\hline 8 & $\begin{array}{l}\text { Reports and presentations of results are } \\
\text { important objects for reproducing LCC practice }\end{array}$ & $\begin{array}{l}\text { 1. Emphasize wide dissemination of results } \\
\text { 2. Include opportunities for cross-departmental } \\
\text { discourse about results }\end{array}$ \\
\hline 9 & $\begin{array}{l}\text { Demonstrating plurality of the lifecycle supports } \\
\text { a deeper understanding of the lifecycle }\end{array}$ & $\begin{array}{l}\text { 1. Do not encourage generic LCC cost models } \\
\text { 2. Use sensitivity analysis }\end{array}$ \\
\hline 10 & $\begin{array}{l}\text { Limitations of using precise data when } \\
\text { conducting LCC }\end{array}$ & $\begin{array}{l}\text { 1. Explain potential data limitations } \\
\text { 2. Provide good examples of companies who have } \\
\text { successfully used LCC despite data limitations }\end{array}$ \\
\hline 11 & $\begin{array}{l}\text { Limitations of using extant costing methods } \\
\text { when conducting LCC e.g. "book value" vs } \\
\text { "market value" }\end{array}$ & $\begin{array}{l}\text { 1. Explain current costing methods' limitations } \\
\text { 2. Suggest relevant costing methods }\end{array}$ \\
\hline 12 & Common words are ascribed diverging meanings & Clearly define key concepts e.g. lifecycle \\
\hline 13 & $\begin{array}{l}\text { Discussions are crucial to making methodological } \\
\text { decisions for LCC }\end{array}$ & Include discursive activities \\
\hline 14 & R\&D engineers have capabilities to perform LCC & Include $R \& D$ engineers if relevant \\
\hline
\end{tabular}

\subsection{Managerial Implications}

Although LCC was introduced in a top down process, its conceptualization as a practice emphasizes that it will be conducted by individual employees who will practice it differently. Therefore management also needs to take into consideration the findings described in Table 2 and work towards creating a common understanding, knowledge and vocabulary from which to practice LCC. A key way of doing this is to provide opportunities to discuss and disseminate LCC results.

Although LCC practice can propel LCM practice, especially when LCM is first introduced in a company, managers must take a strong approach to see that LCC does not undermine the environmental aims by narrowing the lifecycle perspective or excluding environmental burdens.

\subsection{Limitations and Future Research}

Although practice theory is useful for investigating tools and methods, there is danger that, what Nicolini [14] refers to as a weak approach to practice theory, has been used i.e., it is just a rebranding of 
other approaches. The elements of practice presented by Reckwtiz [12] were used to minimize this risk but also created a risk of not viewing practice as a whole. The thick descriptions used are interpretative and thereby hold an inherent possibility for misinterpretations. The observations of the practice are limited by the time frame of the research and the time when the researcher was present.

Moreover, methodologically case studies have known limitations concerning the generalizability of their results [50]. Therefore, more cases studies on LCC as a practice are needed for comparison and further theory building. These types of case studies using practice theory should not be limited to LCC but should be extended to all lifecycle practices included in LCM. None have been identified. There is a general lack of published literature on the relationship between LCC and LCM. Therefore, research using various theoretical approaches and focusing on various aspects of their relationship e.g., practical uses of LCC in LCM, is needed more generally in the area.

Practice theory can be used to investigate, as discussed in Section 6.1, other sustainability-related methods and tools as practices. The learnings about how sustainability practices conform and contest to extant practices and how practices develop over time and in relation to each other should then be used by researchers when developing these methods and tools. This may eventually lead to their increased adoption and more effective use by industry.

Funding: This research was primarily funded by the case company and further supported by the Mistra REES (Resource-Efficient and Effective Solutions) program (No. 2014/16), funded by Mistra (The Swedish Foundation for Strategic Environmental Research).

Acknowledgments: The case company has supported the research by investing both time and money and for this, I am very grateful. I also thank Mattias Lindahl and Tomohiko Sakao, my supervisors, for obtaining the funding for this research and for managing the project and Johannes Matschewsky for joining us on this journey. I would also like to express my gratitude to Göran Goldkuhl and Mattias Lindahl for reading and constructively challenging me on the methodological approach and discussion respectively as well as Kristina Brown for proofreading the document.

Conflicts of Interest: The author declares no known conflict of interest.

\section{References}

1. Commission, B. Our Common Future; Oxford University Press: Oxford, UK, 1987.

2. De Haes, H.A.U.; van Rooijen, M. Life Cycle Approaches: The Road from Analysis to Practice; UNEP/SETAC Life Cycle Initiative: Paris, France, 2005.

3. Westkämper, E.; Alting; Arndt. Life Cycle Management and Assessment: Approaches and Visions Towards Sustainable Manufacturing. Cirp Ann. 2000, 49, 501-526. [CrossRef]

4. Bey, N. Life Cycle Management. In Life Cycle Assessment: Theory and Practice; Hauschild, M., Rosenbaum, R.K., Olsen, S., Eds.; Springer: Berlin/Heidelberg, Germany, 2018.

5. Rebitzer, G.; Hunkeler, D. Life cycle costing in LCM: Ambitions, opportunities, and limitations. Int. J. Life Cycle Assess. 2003, 8, 253-256. [CrossRef]

6. Gluch, P.; Gustafsson, M.; Baumann, H.; Lindahl, G. From tool-making to tool-using-and back: Rationales for adoption and use of LCC. Int. J. Strateg. Prop. Manag. 2018, 22, 179-190. [CrossRef]

7. Korpi, E.; Ala-Risku, T. Life cycle costing: A review of published case studies. Manag. Audit. J. 2008, 23, 240-261. [CrossRef]

8. Higham, A.; Fortune, C.; James, H. Life cycle costing: Evaluating its use in UK practice. Struct. Surv. 2015, 33, 73-87. [CrossRef]

9. D'Incognito, M.; Costantino, N.; Migliaccio, G.C. Actors and barriers to the adoption of LCC and LCA techniques in the built environment. Built Environ. Proj. Asset Manag. 2015, 5, 202-216. [CrossRef]

10. Opoku, A. The application of whole life costing in the UK construction industry: Benefits and Barriers. Int. J. Archit. Eng. Constr. 2013, 2, 35-42. [CrossRef]

11. Hochschorner, E.; Noring, M. Practitioners' use of life cycle costing with environmental costs-A Swedish study. Int. J. Life Cycle Assess. 2011, 16, 897. [CrossRef]

12. Reckwitz, A. Toward a Theory of Social Practices:A Development in Culturalist Theorizing. Eur. J. Soc. Theory 2002, 5, 243-263. [CrossRef] 
13. Schatzki, T.R. Social Practices: A Wittgensteinian Approach to Human Activity and the Social; Cambridge University Press: Cambridge, UK, 1996.

14. Nicolini, D. Practice Theory, Work, and Organization: An Introduction; Oxford University Press: Oxford, UK, 2013.

15. Feldman, M.S.; Orlikowski, W.J. Theorizing Practice and Practicing Theory. Organ. Sci. 2011, 22, 1240-1253. [CrossRef]

16. Cronholm, S.; Goldkuhl, G. Actable Information Systems-Quality Ideals Put Into Practice. In Proceedings of the Eleventh Conference On Information Systems Development (ISD 2002), Riga, Latvia, 12-14 September 2002.

17. Lounsbury, M.; Crumley, E.T. New Practice Creation: An Institutional Perspective on Innovation. Organ. Stud. 2007, 28, 993-1012. [CrossRef]

18. Palo, T.; Åkesson, M.; Löfberg, N. Servitization as business model contestation: A practice approach. J. Bus. Res. 2019, 104, 486-496. [CrossRef]

19. Hunkeler, D.; Lichtenvort, K.; Rebitzer, G. Environmental Life Cycle Costing; Society of Environmental Toxicology and Chemistry (SETAC): Pensacola, FL, USA, 2008.

20. Neugebauer, S.; Forin, S.; Finkbeiner, M. From Life Cycle Costing to Economic Life Cycle Assessment-Introducing an Economic Impact Pathway. Sustainability 2016, 8, 428. [CrossRef]

21. Goh, B.H.; Sun, Y. The development of life-cycle costing for buildings. Build. Res. Inf. 2016, 44, 319-333. [CrossRef]

22. Nilsson-Lindén, H.; Diedrich, A.; Baumann, H. Life Cycle Work: A Process Study of the Emergence and Performance of Life Cycle Practice. Organ. Environ. 2020. [CrossRef]

23. Schmidt, K. Social Practices: A New Focus Area in LCM. In Proceedings of the 6th International Conference on Life Cycle Management, Gothenburg, Sweden, 25-28 August 2013.

24. Seidel-Sterzik, H.; McLaren, S.; Garnevska, E. A Capability Maturity Model for Life Cycle Management at the Industry Sector Level. Sustainability 2018, 10, 2496. [CrossRef]

25. Nicolini, D. Zooming In and Out: Studying Practices by Switching Theoretical Lenses and Trailing Connections. Organ. Stud. 2009, 30, 1391-1418. [CrossRef]

26. Goldkuhl, G. The research practice of practice research: Theorizing and situational inquiry. Syst. Signs Actions 2011, 5, 7-29.

27. Czarniawska, B. On Time, Space, and Action Nets. Organization 2004, 11, 773-791. [CrossRef]

28. Lindberg, K.; Czarniawska, B. Knotting the action net, or organizing between organizations. Scand. J. Manag. 2006, 22, 292-306. [CrossRef]

29. Asiedu, Y.; Gu, P. Product life cycle cost analysis: State of the art review. Int. J. Prod. Res. 1998, 36, 883-908. [CrossRef]

30. IEC. Dependability Management_Part 3-3: Application Guide_Life Cycle Costing, 3rd ed.; International Electrotechnical Commission: Geneva, Switzerland, 2017.

31. Settanni, E.; Newnes, L.B.; Thenent, N.E.; Parry, G.; Goh, Y.M. A through-life costing methodology for use in product-service-systems. Int. J. Prod. Econ. 2014, 153, 161-177. [CrossRef]

32. Hoogmartens, R.; Van Passel, S.; Van Acker, K.; Dubois, M. Bridging the gap between LCA, LCC and CBA as sustainability assessment tools. Environ. Impact Assess. Rev. 2014, 48, 27-33. [CrossRef]

33. Bradley, R.; Jawahir, I.S.; Badurdeen, F.; Rouch, K. A total life cycle cost model (TLCCM) for the circular economy and its application to post-recovery resource allocation. Resour. Conserv. Recycl. 2018, 135, 141-149. [CrossRef]

34. Rodríguez, A.E.; Pezzotta, G.; Pinto, R.; Romero, D. A comprehensive description of the Product-Service Systems' cost estimation process: An integrative review. Int. J. Prod. Econ. 2019, 221, 107481. [CrossRef]

35. Moreau, V.; Weidema, B.P. The computational structure of environmental life cycle costing. Int. J. Life Cycle Assess. 2015, 20, 1359-1363. [CrossRef]

36. De Giacomo, M.R.; Testa, F.; Iraldo, F.; Formentini, M. Does Green Public Procurement lead to Life Cycle Costing (LCC) adoption? J. Purch. Supply Manag. 2019, 25, 100500. [CrossRef]

37. Stark, J. Product Lifecycle Management: 21st Century Paradigm for Product Realisation, 2nd ed.; Springer: London, UK, 2011.

38. Remmen, A.; Jensen, A.A.; Frydendal, J. Life Cycle Management: A Business Guide to Sustainability; UNEP/Earthprint: Nairobi, Kenya, 2007. 
39. Bierer, A.; Götze, U.; Meynerts, L.; Sygulla, R. Integrating life cycle costing and life cycle assessment using extended material flow cost accounting. J. Clean. Prod. 2015, 108, 1289-1301. [CrossRef]

40. Gluch, P.; Baumann, H. The life cycle costing (LCC) approach: A conceptual discussion of its usefulness for environmental decision-making. Build. Environ. 2004, 39, 571-580. [CrossRef]

41. Boehm, M.; Thomas, O. Looking beyond the rim of one's teacup: A multidisciplinary literature review of Product-Service Systems in Information Systems, Business Management, and Engineering \& Design. J. Clean. Prod. 2013, 51, 245-260. [CrossRef]

42. Tukker, A. Product services for a resource-efficient and circular economy-A review. J. Clean. Prod. 2015, 97, 76-91. [CrossRef]

43. Meier, H.; Roy, R.; Seliger, G. Industrial Product-Service Systems-IPS 2. Cirp Ann. 2010, 59, $607-627$. [CrossRef]

44. Matschewsky, J.; Kambanou, M.L.; Sakao, T. Designing and providing integrated productservice systems-Challenges, opportunities and solutions resulting from prescriptive approaches in two industrial companies. Int. J. Prod. Res. 2017, 56, 2150-2168. [CrossRef]

45. Martinez, V.; Bastl, M.; Kingston, J.; Evans, S. Challenges in transforming manufacturing organisations into product-service providers. J. Manuf. Technol. Manag. 2010, 21, 449-469. [CrossRef]

46. Pagoropoulos, A. Product/Service-Systems in the Maritime Industry-From Economic Evaluation Throughout the Life Cycle to Implementation; Technical University of Denmark: Lingbi, Denmark, 2017.

47. Kohtamäki, M.; Baines, T.; Rabetino, R.; Bigdeli, A.Z. Practices in Servitization. In Practices and Tools for Servitization; Kohtamäki, M., Baines, T., Rabetino, R., Bigdeli, A.Z., Eds.; Palgrave Macmillan: Cham, Switzerland, 2018.

48. Pettigrew, A.M. Longitudinal Field Research on Change: Theory and Practice. Organ. Sci. 1990, 1, $267-292$. [CrossRef]

49. Eisenhardt, K.M. Building Theories from Case Study Research. Acad. Manag. Rev. 1989, 14, 532-550. [CrossRef]

50. Yin, R.K. Case Study Research: Design and Methods, 5th ed.; SAGE Publications: London, UK, 2014.

51. Given, L.M. The Sage Encyclopedia of Qualitative Research Methods; SAGE Online: Thousand Oaks, CA, USA, 2008.

52. Schwandt, T.A. The Sage Dictionary of Qualitative Inquiry; SAGE Publications: Thousand Oaks, CA, USA, 2014.

53. Flick, U. An Introduction to Qualitative Research; SAGE Publications: Thousand Oaks, CA, USA, 2018.

54. Patton, M.Q. Qualitative Research E Evaluation Methods; SAGE: Thousand Oaks, CA, USA, 2002.

55. Baumann, H.; Tillman, A.-M. The Hitchhiker's Guide to LCA: An Orientation in Life Cycle Assessment Methodology and Application; Studentlitteratur: Lund, Sweden, 2004.

56. Lindahl, M.; Sundin, E.; Sakao, T. Environmental and economic benefits of Integrated Product Service Offerings quantified with real business cases. J. Clean. Prod. 2014, 64, 288-296. [CrossRef]

57. Sassanelli, C.; Rosa, P.; Rocca, R.; Terzi, S. Circular economy performance assessment methods: A systematic literature review. J. Clean. Prod. 2019, 229, 440-453. [CrossRef]

58. Rossi, M.; Germani, M.; Zamagni, A. Review of ecodesign methods and tools. Barriers and strategies for an effective implementation in industrial companies. J. Clean. Prod. 2016, 129, 361-373. [CrossRef]

59. Jasinski, D.; Meredith, J.; Kirwan, K. A comprehensive review of full cost accounting methods and their applicability to the automotive industry. J. Clean. Prod. 2015, 108, 1123-1139. [CrossRef]

60. Angelakoglou, K.; Gaidajis, G. A review of methods contributing to the assessment of the environmental sustainability of industrial systems. J. Clean. Prod. 2015, 108, 725-747. [CrossRef]

61. Woodward, D.G. Life cycle costing-Theory, information acquisition and application. Int. J. Proj. Manag. 1997, 15, 335-344. [CrossRef]

(C) 2020 by the author. Licensee MDPI, Basel, Switzerland. This article is an open access article distributed under the terms and conditions of the Creative Commons Attribution (CC BY) license (http://creativecommons.org/licenses/by/4.0/). 